resistance (particularly at the lower bureaucratic-administrative levels) to innovation as such. Dr Amann also points to the phenomenon of variations in the technological level of Soviet industry, duly illustrated by the case study approach which occupies Chapters 2-8 and covers the machine-tool industry, Group Technology, the "chemicalisation drive", the management automation programme, control instrumentation for industrial processes and the Soviet defence industry. Here the inclusion of Group Technology and management automation (closely connected with developments in machine tools and computers respectively) represents an addition to the investigations pursued in The Technological Level of Soviet Industry, the precursor to the present volume published in 1977.

Dr Amann properly advises on the limitations of the case study approach, though I should echo his point that each of the studies included here is virtually a monograph in its own right. If there is a Soviet success story, then it might be found in John Grayson's elegant and hugely informative study of Soviet Group Technology (GT), the value of which is further enhanced by the tabular presentation of GT outside the USSR, including innovations in Eastern Europe. New also to this volume is the extensive treatment by Dr Cave of the Soviet automated management programme (ASU), which dwells in welcome detail on Soviet computer developments since 1973 and evaluates the problems of the Soviet computer automation programme as a whole. Nevertheless, it might have been useful to to have looked more closely at the military automation programme (ASUV) which can fairly be described as a significant aspect of the Soviet "management" scene, if only because upravlenie ("management" plus control direction) hides a teeming complexity of issues facing soldier and civilian alike.

The civilian-military interface (or the lack of it) is also germane to David Holloway's two contributions devoted to the defence sector. The first (and more important) of his chapters deals with the system and its structures, especially military R\&D organization; the second examines innovation in the field of ICBMs and main battle tanks. Undoubtedly the highest priority goes to military programmes (where innovation can be stimulated by personal interests expressed by the highest leadership level), though the accepted notion of an absolute distinction between military and civilian sectors is open to doubt. This last, a key question, is most admirably and ably explored by $\mathrm{Mr}$ Holloway. As for military technology itself, this requires the closest scrutiny and here it would seem that tank technology is not entirely Mr Holloway's forte. Are we talking about design or innovation or both? It should also be noted that there has indeed been a change in the relationship between the Soviet tank forces and the design/production organization: quite recently Colonel-General (Tank Troops) Yu. Potapov was invested with direct responsibility for $R \& D$ on armoured fighting vehicles within the Defence Ministry. This could suggest that all is not well with the T-72 and that there is a demand for a real technology jump with the T-80: moreover, what, if anything is to come of Soviet interest in HIMAG (High Mobility/Agility Vehicle) developments?

This volume is not only impressive but quite invaluable, if only for dispelling myths or combating ignorance. The specialist will no doubt dote on his own section, but the book ought to be used by a wide range of individuals and agencies - academic, professional or in government (especially the latter). The insights and information are demonstrably significant, the scholarship is formidable; I might however put in a small plea for a composite bibliography, the better to take advantage of key but little known Soviet publications. The further volume which is promised can only be an ornament to this illustrious enterprise, but for the moment the message of the present book is reasonably plain: over to you, Mr Andropov.

John Erickson is Director of Defence Studies in the Department of Politics, University of Edinburgh. Among other books he is author of Soviet Military Power and Performance (Macmillan, London, 1971).

\title{
A New World of ferns and their relations
}

\section{Peter H. Raven}

Ferns and Allied Plants: with Special Reference to Tropical America. By Rolla M. and Alice F. Tryon. Pp.857. ISBN 3-54090672-X. (Springer-Verlag: 1982.) \$167.80.

THIS magnificently illustrated and beautifully prepared book constitutes a detailed account of the 127 genera of the ferns and other groups of "lower" vascular plants that occur in the Western Hemisphere. It is based on an assessment of the wealth of new information that has become available during the past few decades, as well as on the research of the authors themselves, who have laboured for many years to produce what has turned out to be a masterly synthesis of our knowledge of this group of plants.

The authors adopt a relatively conservative taxonomic treatment with respect to the families of ferns and other vascular plants that do not form seeds, recognizing 33 families (29 of which are treated in this volume), 240 genera and about 9,000 species. They believe that the recognition of more inclusive taxa often reflects relationships better than subdivision to emphasize differences. Since more than half of the genera of ferns are treated in this book in detail, and almost all are discussed to some extent, the work approaches the dimensions of a global survey and will prove invaluable for studies of the group anywhere in the world.

About three-quarters of all ferns occur in the tropics, with nearly half of these (about 3,000 species) in tropical America and an additional 250 species in extratropical North and South America. In the Greater Antilles, southern Mexico and Central America, the northern Andean region (with about 1,500 species, or about a sixth of all species of ferns in the world!), and coastal southeastern Brazil, there are striking centres of endemism among the ferns. In contrast, the Amazon Basin is relatively poor in species of ferns, with only about 300 species in the entire Amazonian region of Brazil, or about a fifth as many as there are in the northern Andean region.

Particularly outstanding is the Tryons' discussion of the spores of ferns, which highlights evolutionary trends, including the line from trilete to monolete apertures and that which leads to the elaborated surface contours derived from the perispores that occur in advanced families.

A treatment of a typical genus in the book includes generic synonymy (except in a few cases where the related Old Word genera are especially complex); a description; an overall account of the numbers of species and of the generic subdivisions, if any; a special account and often enumeration of the species found in tropical America; remarks on ecology, geography, spores and cytology; general observations; a distribution map of the genus; supplementary illustrations; and citations literature. The text is supported by handsome black-and-white photographs (taken primarily by Walter $\mathrm{H}$. Hodge) and by scanning electron micrographs of the spores of the various genera.

All of these features add up to make the book a notable contribution to our understanding of this large and often ecologically important group of plants. It certainly deserves a place in every library that attempts to have a collection of the most basic botanical works; in addition many individuals will wish to purchase it, whether or not they have a specialist interest in ferns. One can but applaud and congratulate the authors on having brought this major and original contribution to knowledge to such a satisfactory conclusion.

Peter H. Raven is Director of the Missouri Botanical Garden and Engelmann Professor of Botany at Washington University, St Louis. 